\title{
Application of Low-Cost Sensors for the Development of a Methodology to Design Front-End Loaders for Tractors
}

\author{
H. Malon $\triangle{ }^{1}$ A. Ayuda, ${ }^{1}$ F. J. Garcia-Ramos $\mathbb{D}^{2}{ }^{2}$ M. Vidal, ${ }^{1}$ and J. Cuartero ${ }^{1}$ \\ ${ }^{1}$ Departamento de Ingeniería Mecánica, Escuela de Ingeniería y Arquitectura, University of Zaragoza, 50018, Spain \\ ${ }^{2}$ Departamento de Ciencias Agrarias y del Medio Rural, Escuela Politécnica Superior, University of Zaragoza, C/Cuarte s/n, \\ 22004 Huesca, Spain
}

Correspondence should be addressed to H. Malon; hml@unizar.es

Received 22 November 2019; Revised 27 January 2020; Accepted 5 February 2020; Published 28 February 2020

Guest Editor: Jingwei Wang

Copyright $\odot 2020 \mathrm{H}$. Malon et al. This is an open access article distributed under the Creative Commons Attribution License, which permits unrestricted use, distribution, and reproduction in any medium, provided the original work is properly cited.

Tractor front-end loaders are an essential part of the equipment used on farms. At present, there are an important number of smalland medium-sized companies involved in the manufacturing of this equipment. These companies rely heavily on experience for innovative designs, as in the vast majority of cases they lack access to adequate methodology for the optimal design of new front-end loaders. The study conducted has developed a methodology to design tractor front-end loaders with a view of obtaining their accurate design during the bucket loading process. The methodology comprises two phases: the first phase involves a numerical analysis of the structural behaviour of the front-end loader components by means of the Finite Element Method; the second phase, the experimental phase, makes use of low-cost sensors, in particular, strain gauges, to analyse existing strains at selected points in the front-end loader structure. The experimental results obtained by means of low-cost sensors fitted onto the front-end loader allow analysing the existing strains at the points measured, as well as validate the numerical model developed. This methodology is validated by applying it to a commercial front-end loader, more specifically to model 430E2 of the company Maquinaria Agrícola El León S.A (Spain).

\section{Introduction}

Tractor front-end loaders are frequently used in the daily tasks carried out on agricultural holdings [1]. A loader is fitted to the front part of the tractor so as to carry or move loads around [2]. There are currently an important number of small- and medium-sized companies involved in the manufacturing of this equipment. These companies heavily rely on its experience for design, as in the vast majority of cases they lack access to adequate methodology for the optimal design of new front-end loaders. Current methodology used by these companies does not include traditional experimental testing. On the contrary, after the manufacture of a prototype, companies analyse its operation thanks to the help of reliable customers who detect faults in it which are used to improve its design. In this methodology, the manufacturer does not have an exhaustive control of the work carried out by the machine. For this reason, it is not possible to confirm whether the failures indicated by the customer are really due to a design failure or to a misuse of the prototype.

While some studies deal with tractor loaders [3-5], no reference to the structural behaviour of the loader is made in them. Likewise, those studies analysing the structural safety of front-end loaders focus on the study of impact loads $[2,6]$.

Technical experts point out that most damage occurring to the structure of a front-end loader fitted to a tractor stems from the misuse of the equipment during the carrying out of daily tasks. More specifically, the majority of the defects detected are plastic strains or even breaking of welded joints in the resistant structure, which occur as a result of the misuse of these devices during the loading manoeuvres where the bucket is involved. The most frequent instances of misuse are the excessive speed of tractor in the bucket loading process or the use of the bucket to pull down walls or uproot trees. Both instances lead to the same outcome: there is a point in time 
when the bucket is unable to move forward while the tractor keeps doing so. This fact results in a deformation of the resistant structure of the front-end loader, leading to plastic strains or even the breaking of some welded joints.

Thus, it is evident that there is a need for a methodology to develop the design of front-end loaders mounted on tractors during the bucket loading process. This methodology must allow obtaining the strains and stresses at the selected points of the front-end loader structure. The results should be obtained by means of low-cost sensors, specifically strain gauges. The use of these types of sensors is widespread as a technique for the structural analysis of components of metal structures in general [7-10]. In addition, this methodology must allow analysing the structural behaviour of each component of the front-end loader by means of numerical techniques based on the Finite Element Method (FEM). The structural analysis by means of the FEM is a technology with a proven track record frequently used for the analysis of vehicles $[9,11-16]$ and more recently in some agricultural implements $[6,17,18]$. Moreover, it is necessary to define two manoeuvres: static and dynamic. The static manoeuvre allows analysing the structural behaviour of the front-end loader in a load case in which load is known. On the other hand, the dynamic manoeuvre allows analysing the structural behaviour of the front-end loader in a load case in which load is unknown.

\section{Objective}

The main objective of this study is to develop and validate a methodology for the design and development of front-end loaders for agricultural tractors, which can be used by companies that do not have resources to apply expensive design methodologies. In order to achieve the comprehensive objective of this project, two technical objectives need to be met: the definition of an experimental test phase and a numerical analysis phase. The experimental test phase is aimed at obtaining, by means of low-cost sensors, more specifically strain gauges, the strains and stresses generated at the front-end loader structure during the bucket loading process, where most damage occurs. Likewise, the aim of the numerical analysis phase is to obtain the comprehensive structural behaviour of a front-end loader mounted on a tractor during the bucket loading process.

\section{Materials and Methods}

The methodology is made up of two phases. In the first phase (experimental), low-cost sensors-more specifically strain gauges - are used to measure strains and stresses at selected points of the front-end loader structure. In the second phase (numerical analysis), the structural behaviour of the frontend loader components are analysed by means of the FEM.

The methodology developed has been validated through its application to a commercial front-end loader, more specifically to a 430E2 model of Maquinaria Agrícola El León Company (Spain). The technical specifications have been obtained from its commercial brochure [19], as well as from information provided by the company itself.

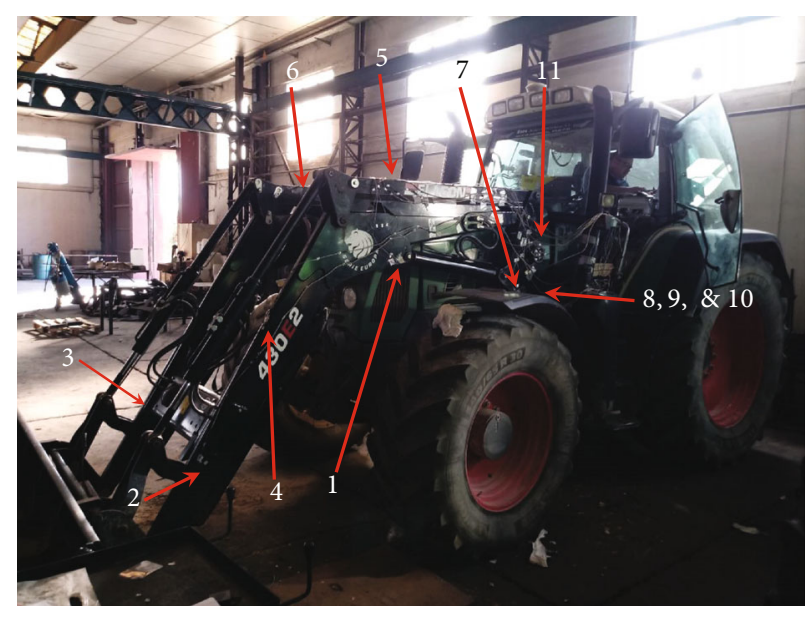

Figure 1: Front loader 430E2 mounted on a FENDT 718 Vario tractor.

The method used during the experimental and numerical analysis phases is described below.

3.1. Experimental Phase. For the experimental test, a frontend loader 430E2 was mounted on a FENDT 718 Vario tractor, as shown in Figure 1.

Once the front-end loader was coupled, 11 low-cost sensors were fitted, more specifically 9 unidirectional strain gauges and 2 rosettes. A rosette is a sensor with multiple strain gauges on a common carrier. The rosettes used in the study are composed by three strain gauges [20]. In addition, a further unidirectional strain gauge (in a total series of ten strain gauges) was used, so as to perform due corrections arising from temperature effects. Table 1 describes the position where the strain gauges were placed. Figure 1 shows the position of sensors on the front-end loader. Figures 2 and 3 show in detail rosette 1 and strain gauges 8 and 10 , respectively.

The strain gauge signals were recorded by a strain gauge measurement system (StrainBook/616, Measurement Computing, Norton, MA, USA). This equipment allows simultaneous measurements of twenty-four channels. The measurement system was connected to a laptop computer equipped with data acquisition software (Waveview 7.15, Measurement Computing).

During this phase, two types of tests were defined. The first involved a static load test, while the second one was a dynamic load test. These tests were conducted in the facilities of Virgen de la Oliva Cooperative, in Ejea de los Caballeros (Spain), while the Cooperative was open. The experimental tests had to be conducted with the tractor engine running for safety reasons. This fact implies the presence of vibrations in the front loader transmitted by the tractor engine.

The acquisition frequency used for the recording of data during the tests was $1 \mathrm{~Hz}$ for the static load case and $50 \mathrm{~Hz}$ for the dynamic load test.

3.1.1. Static Load Test. Strains and stresses were obtained for the case of a mass of $320 \mathrm{~kg}$ placed in the loader bucket. To 
TABLE 1: Location of the strain gauges.

\begin{tabular}{|c|c|}
\hline Strain gauge & Location \\
\hline 1 & Rosette fitted onto the left longitudinal beam in front of the fastening blot for the hydraulic cylinder \\
\hline 2 & Unidirectional strain gauge placed onto the front area of the left longitudinal beam, close to the crossbeam gap \\
\hline 3 & Unidirectional strain gauge attached to the right longitudinal beam, in a symmetric position to strain gauge 2 \\
\hline 4 & Unidirectional strain gauge located at the upper fold of the left longitudinal beam \\
\hline 5 & Unidirectional strain gauges placed at the top of the parallelogram beams of the left longitudinal beam \\
\hline 6 & $\begin{array}{l}\text { Unidirectional strain gauges placed at the top of the parallelogram beams of the right longitudinal beam, } \\
\text { in a symmetric position to strain gauge } 5\end{array}$ \\
\hline 7 & Unidirectional strain gauge located at the lower area of the outer surface of the front-end loader left support \\
\hline 8 & Rosette was placed close to the support area of the front-end loader in the clamping pillar \\
\hline 9 & $\begin{array}{l}\text { Unidirectional strain gauge fitted onto the front face of the clamping pillar, at the same height } \\
\text { where the clamping pillar is attached to the tractor chassis }\end{array}$ \\
\hline 10 & Unidirectional strain gauge placed on the rear face of the clamping pillar \\
\hline 11 & $\begin{array}{l}\text { Unidirectional strain gauge placed onto the outer surface of the front loader left support, } \\
\text { close to the loader's lock-in mechanism }\end{array}$ \\
\hline
\end{tabular}

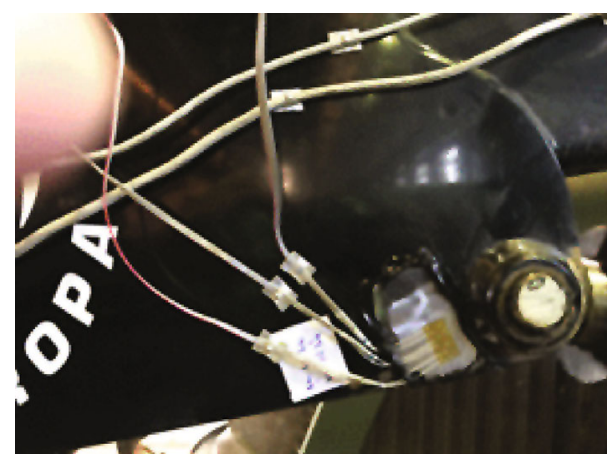

FIGURE 2: Gauge 1: rosette placed at the left longitudinal beam.

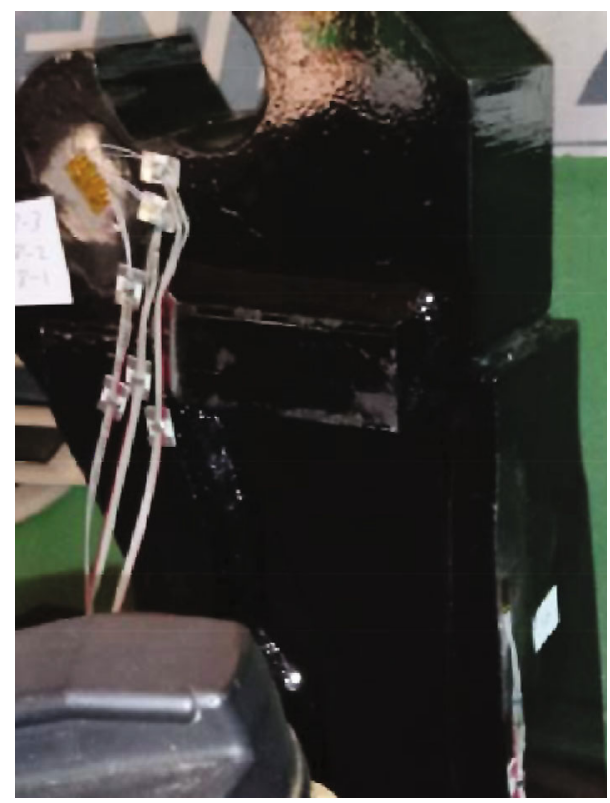

FIgURE 3: Strain gauges 8 and 10 placed at the left clamping pillar. that aim, 8 bags of fertiliser, with a mass of $40 \mathrm{~kg}$ each, were located in the loader bucket. They were evenly distributed on the bucket surface. Once the mass was in place, the position of the front-end loader was maintained for at least $60 \mathrm{~s}$, so as to obtain a steady record of stresses and strains. In the test conducted, the time of the loading process was 88 seconds and the time of maintaining the position was 86 seconds.

The front loader's bucket base was placed horizontally, $5 \mathrm{~cm}$ high from the ground. Figure 4 shows the position of the front-end loader and the even distribution of the bags for the static load case.

3.1.2. Dynamic Load Test. The dynamic load test seeks to analyse the behaviour of the structural components of a front-end loader during the loading process. The usual loading process with this type of equipment consists of placing the bucket in a horizontal position on the ground while the tractor drives forward. During this process, the bucket fitted to the front-end loader is shoved into the heap of the material to load, generally grain, fertiliser, or soil. The bucket is subsequently turned upwards, thus ending the bucket loading process. Figure 5 shows the front-end loader and its load, in this case, of fertiliser.

To define the test, the possibility of defining a dynamic essay with real-life loads was ruled out, owing to its low repeatability, given the high variability in the density of the materials used (grain, fertiliser, and soil) associated to changeable environmental conditions. Instead, a dynamic experimental test showing high repeatability was designed. Thus, the ensemble formed by the tractor and front loader was set to push against a concrete loading bay. To execute this action, the front loader was placed onto the ground, with its bucket placed in a horizontal position. The contact with the loading bay by the ensemble formed by the tractor and the front loader occurred at the front part of the front loader's bucket. Figure 6 shows how the tractor-front loader ensemble is positioned during the execution of the dynamic load test. The same manoeuvre was performed twice. Data from strain gauges was recorded at a frequency of $50 \mathrm{~Hz}$. 


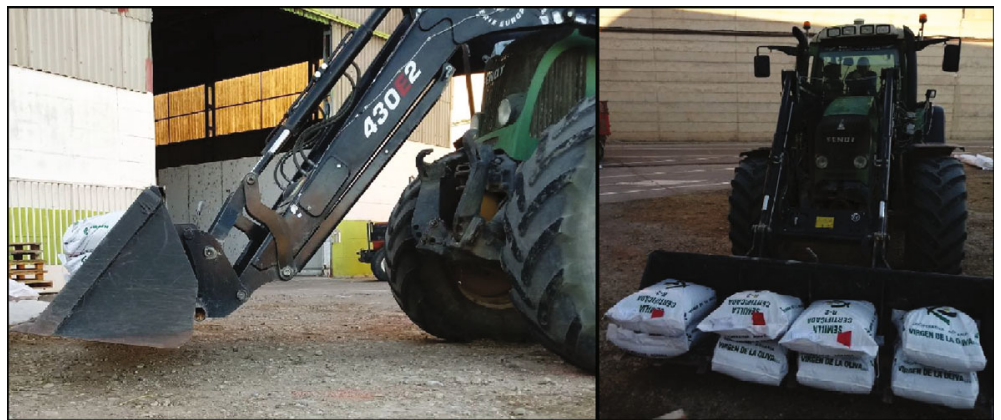

Figure 4: Positioning of the front-end loader and distribution of bags for the static load test.

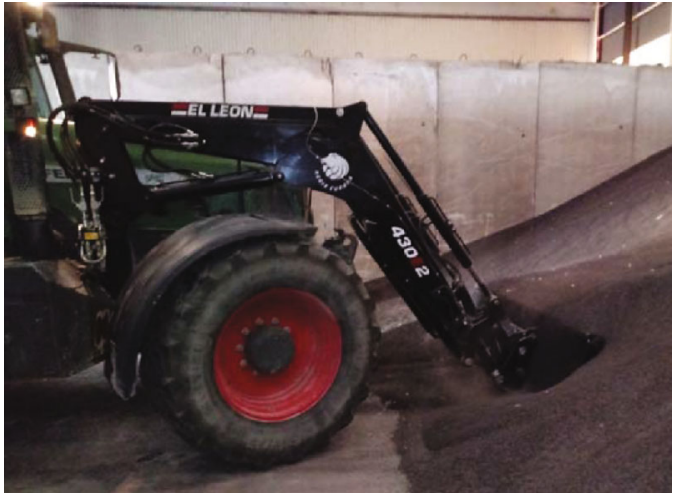

Figure 5: Fertiliser load in the front loader.

The execution of the dynamic test allows obtaining the strains and stresses undergone during the front loader load process for any material, with high repeatability regardless of environmental conditions, getting to the critical point where the tractor fails to move any further.

3.2. Numerical Analysis Phase. During the study conducted, the front-end loader was modelled. The numerical model (Figure 7) was formed by 71,039 nodes and 64,294 elements. For the discretization of the front loader structural components (shown in grey in Figure 7), shell-type elements were used. Shell-type elements were also used for the bucket model, shown in blue in Figure 7. The clamping pillar of the tractor (in green in Figure 7) was discretized by means of volumetric elements. The modelling of the hydraulic cylinders and bolts of the movable joints in the front-end loader was carried out by means of beam-type elements, as shown in red in Figure 7. Multipoint constraints (MPCs) were used to avoid completely rigid joints between bolts and bush and thus replicate their actual behaviour.

The material used in the numerical analysis in all components for the front loader, the bucket, and the clamping pillars has been Steel S355-JR. On the other hand, linear elastic steel has been applied for the hydraulic cylinders and bolts. The mechanical properties of the steels used are shown in Table 2.

Similar to the experimental phase, two load cases have been defined for the numerical analysis. The first one was a static load case, whereas the second was a dynamic load case. Both tests are described in detail below.
3.2.1. Static Load Case. The static load case is aimed at analysing the comprehensive structural behaviour of the front loader in terms of stiffness and strength when known loads are applied to it. The numerical analysis has been carried out by means of the software Abaqus 6.14-2, with a standard formulation for the analysis of a static load case.

To perform the numerical analysis, the ensemble bucketfront loader was positioned with the bucket base horizontal $5 \mathrm{~cm}$ high from the ground.

The load applied corresponds to a descending vertical force of $3,136 \mathrm{~N}$, evenly distributed over the base of the bucket in the numerical model. This is shown in blue in Figure 8 . The load applied corresponds to the weight used in the experimental phase $(320 \mathrm{~kg})$.

As for the boundary conditions defined in the numerical analysis, displacements were restricted in the bores for the attachment bolts of the clamping pillars to the tractor. These areas where displacements were restricted for the numerical analysis are shown in red in Figure 8.

3.2.2. Dynamic Load Case. The dynamic load case is aimed at analysing the structural behaviour of the front-end loader in terms of stiffness and strength during the loading process. The numerical analysis has been carried out by means of the commercial software Abaqus 6.14-2, with explicit formulation for the analysis of a dynamic load case.

In the numerical model, the loader-bucket set has been placed in the low position, with the base of the bucket in horizontal position.

For this load case, a forward displacement of the tractor rather than a force has been selected. More specifically, the load case under analysis consisted in a $50 \mathrm{~mm}$ forward movement in 1 second. This forward movement was defined taking into account the information provided by technical experts in the manufacturing of tractor front loaders. The forward movement was applied at the bores of the attachment bolts of the clamping pillars to the tractor. The clamping pillars convey displacement of the tractor's chassis to the front-end loader in real life. The zones where the forward movement was applied are shown in red in Figure 9.

The imposed boundary conditions restricted displacement in forward direction of the tractor at the frontal line nodes of the bucket base. These nodes are shown in blue in Figure 9. 


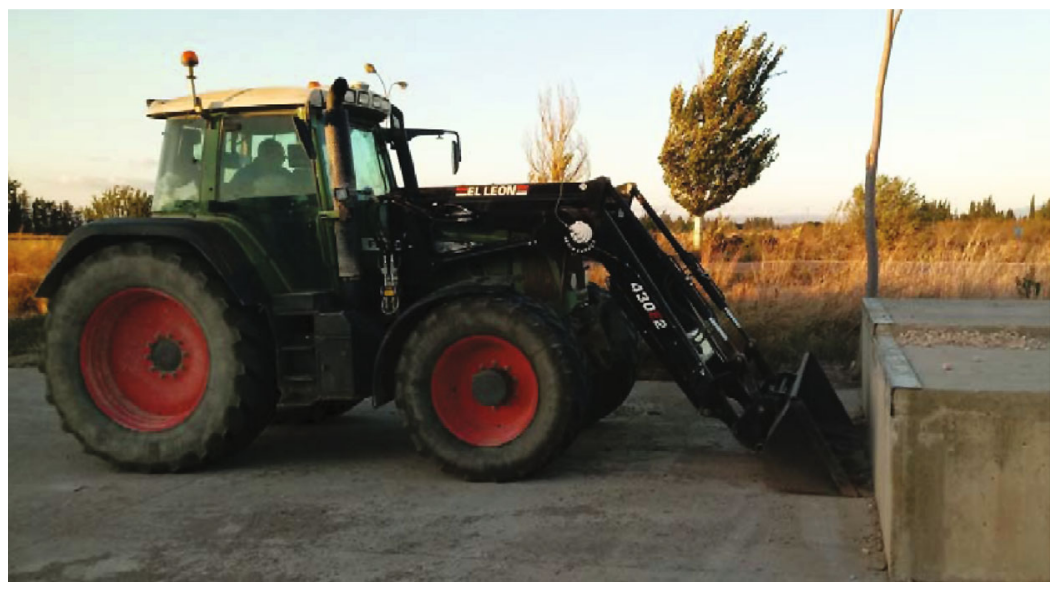

Figure 6: Dynamic load test.

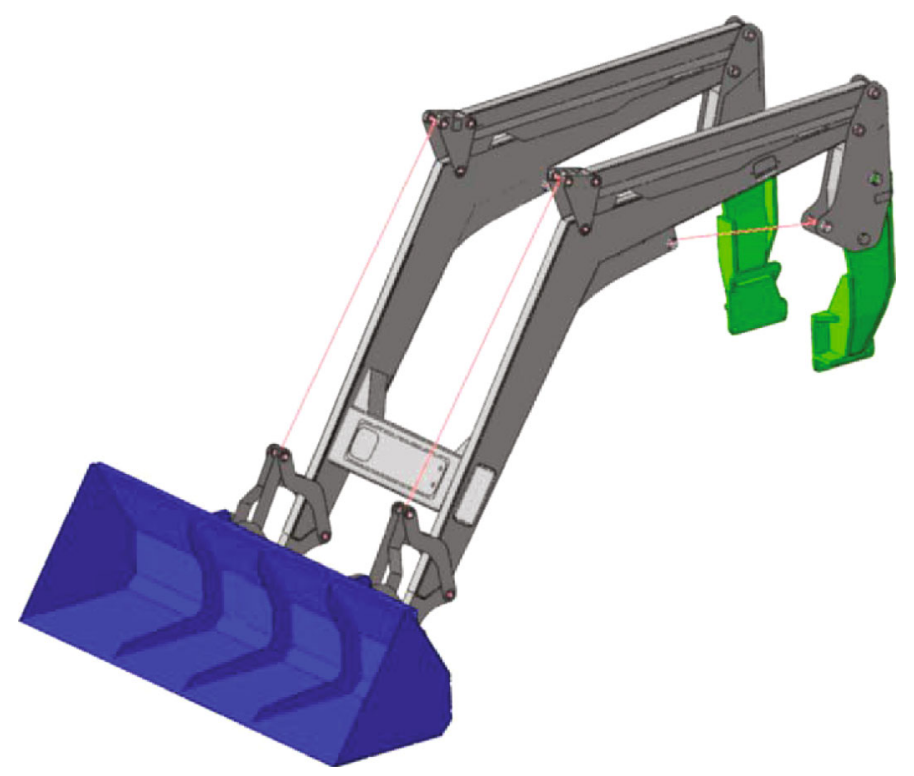

Figure 7: Numerical model of front-end loader 430E2.

TABLE 2: Mechanical properties of steels used in the numerical model.

\begin{tabular}{|c|c|c|c|c|c|c|}
\hline Material & Density $\left(\mathrm{kg} / \mathrm{m}^{3}\right)$ & Young's modulus (MPa) & Poisson's ratio & Yield strength $(\mathrm{MPa})$ & Tensile strength $(\mathrm{MPa})$ & Elongation (\%) \\
\hline Steel S355 & 7,800 & 210,000 & 0.3 & 355 & 470 & 17 \\
\hline Steel & 7,800 & 210,000 & 0.3 & & & \\
\hline
\end{tabular}

\section{Results and Discussion}

\subsection{Experimental Phase}

4.1.1. Static Load Test. In the static load test conducted, the time of the loading process was 88 seconds and the time of maintaining the load was 86 seconds. The results of the static load test obtained are shown in Figures 10 and 11. These figures show the values of microstrains $(\mu \varepsilon)$ from unidirectional strain gauges, as well as Von Mises stress values obtained from the rosettes. It must be pointed out that the metering channels associated to unidirectional strain gauges 6 and 9 were damaged during the journey to the test area, and therefore, they recorded no strain variations over the entirety of the tests performed.

The mean values as well as standard deviation of recorded data from the 9 low-cost sensors during the test are shown in Table 3.

The results obtained provide evidence that the load level in the front loader was very low, with mean stress values for rosettes 1 and 8 of 11.7 and 7.3 $\mathrm{MPa}$, respectively, and maximum mean strain values of $88 \mu \varepsilon$ from unidirectional strain 


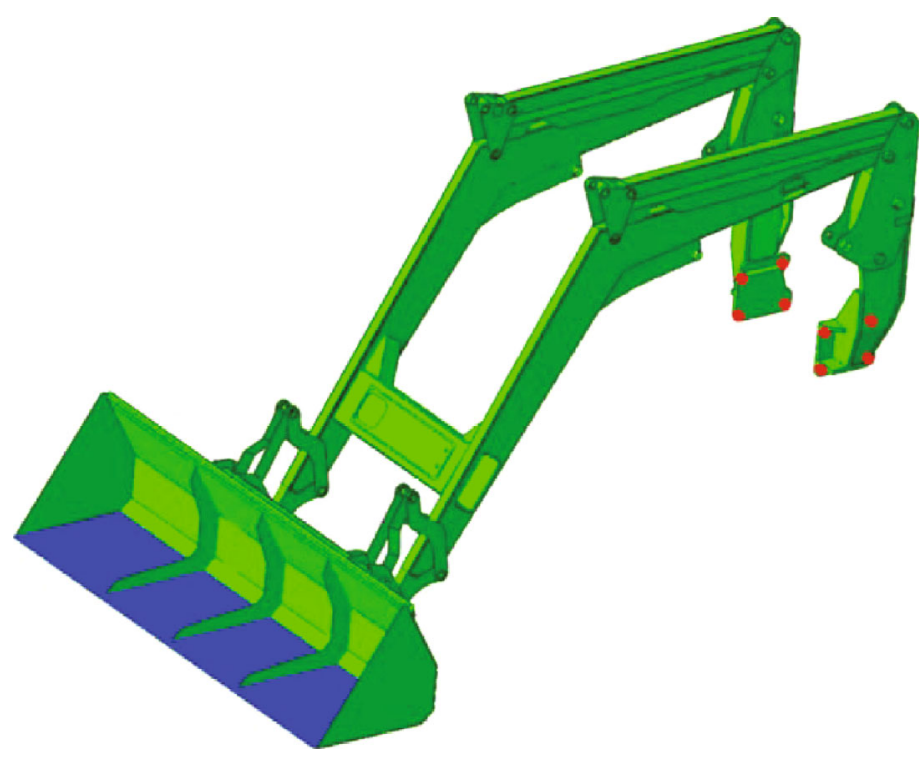

FIgURE 8: Areas where load (blue) and boundary conditions (red) were applied in the static load case.

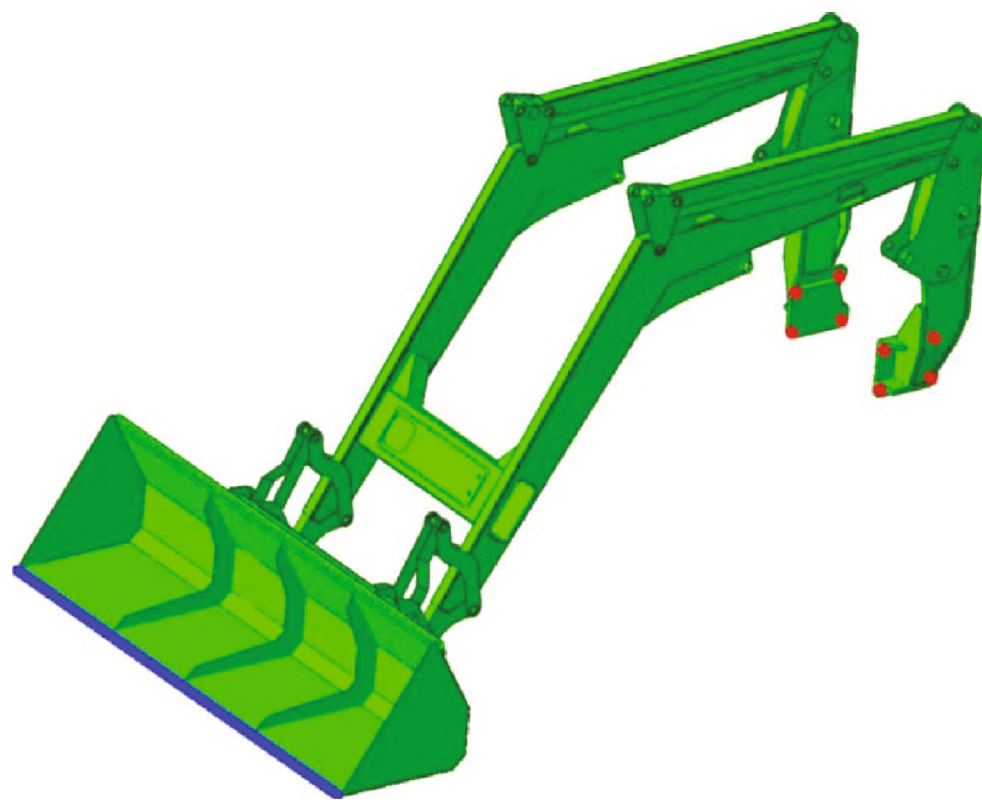

Figure 9: Areas where load (red) and boundary conditions (blue) were applied in the dynamic load case.

gauge 10. These results are consistent with the load applied during the experimental test $(320 \mathrm{~kg})$ with respect to the maximum admissible load for the bucket in the defined position $(3,400 \mathrm{~kg})$.

Standard deviations obtained from gauges 2 and 3 show high values with respect to the mean. However, two considerations must be taken into account when analysing these results. The first one concerns the location of these gauges. Gauges 2 and 3 were placed in the overhang of the loader, where the vibrations generated by the tractor engine in operation had greater effect. Secondly, the average value recorded by these gauges ( $1 \mu \varepsilon$ and $6 \mu \varepsilon$, respectively) was very low. These values are equivalent to a unidirectional stress of $0.21 \mathrm{MPa}$ and 1.26 MPa, respectively. In addition, the results obtained from strain gauge 2 were in a range between $+5 \mu \varepsilon$ and $-2 \mu \varepsilon$, while for gauge 3 the range was between $9 \mu \varepsilon$ and $2 \mu \varepsilon$. These results show that the strain variations were less than $7 \mu \varepsilon$ (equivalent to a unidirectional stress of $1.47 \mathrm{MPa}$ ) in both gauges. These minor variations generate that the standard deviations have a high value with respect to the mean, because the strain values recorded are very low.

On the other hand, the results obtained from the gauges placed in more stable areas of the front-end loader structure (gauge 10 placed in the clamping pillar or gauge 11 placed in the left support) had a minor standard deviation in relation to the mean. In addition, these areas were subject to greater efforts generated by the loading placed in the loader bucket. 


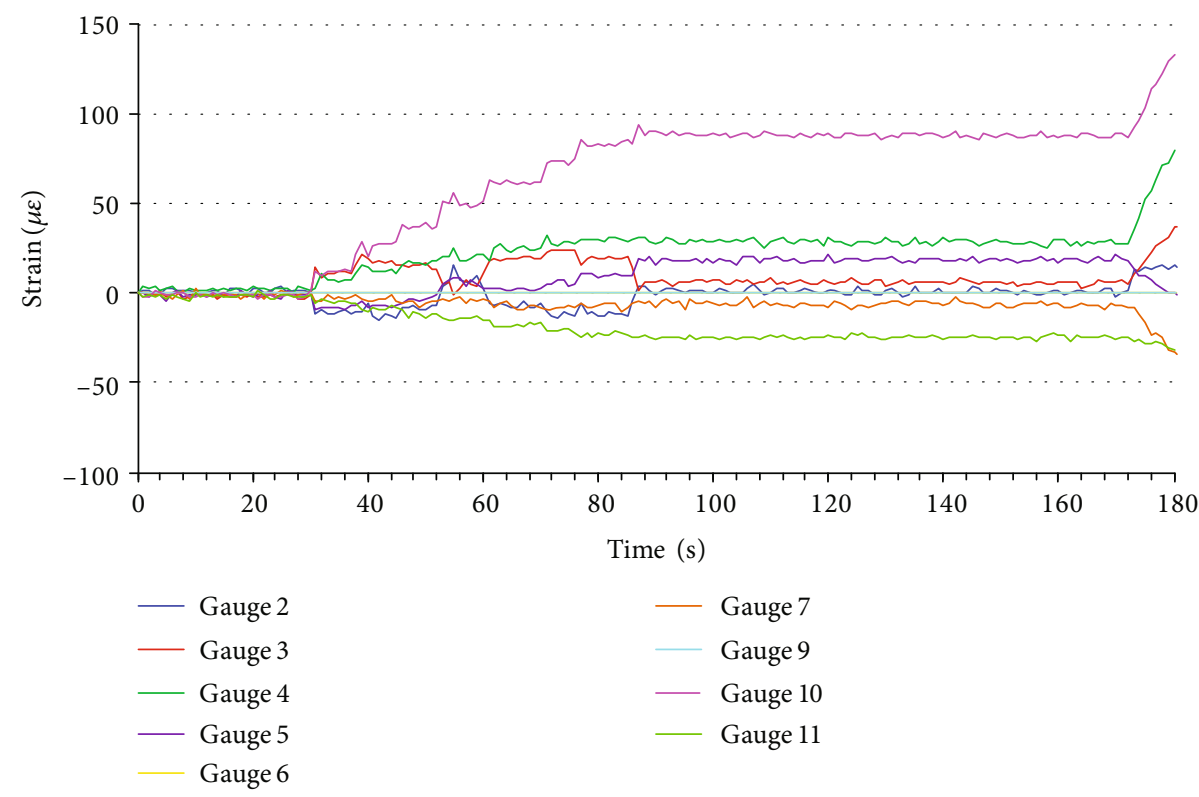

FIgURE 10: Results from unidirectional strain gauges from the static load test.

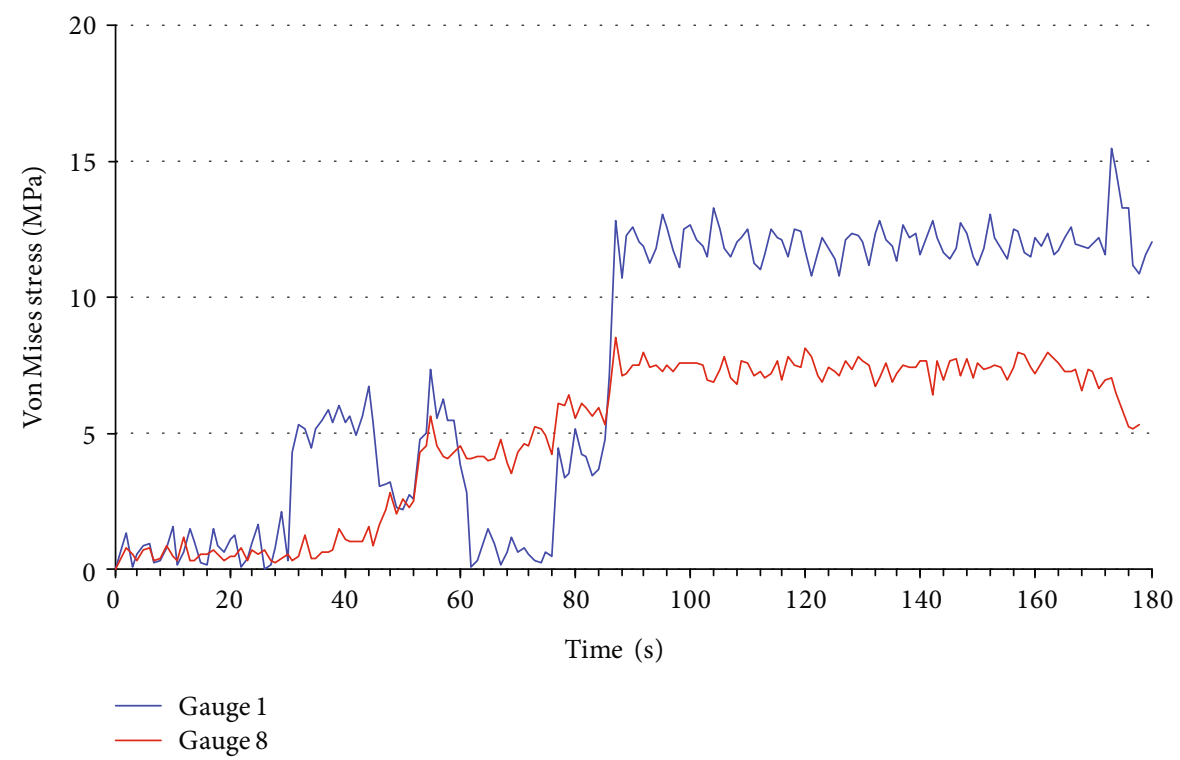

FIgURE 11: Results from the rosettes from the static load test.

TABLE 3: Mean and standard deviation values from the static load test.

\begin{tabular}{lccccccccc}
\hline & & & \multicolumn{3}{c}{ Gauges } & & \\
& $1(\mathrm{MPa})$ & $2(\mu \varepsilon)$ & $3(\mu \varepsilon)$ & $4(\mu \varepsilon)$ & $5(\mu \varepsilon)$ & $7(\mu \varepsilon)$ & $8(\mathrm{MPa})$ & $10(\mu \varepsilon)$ & $11(\mu \varepsilon)$ \\
\hline Mean & 11.7 & 1 & 6 & 29 & 18 & -6 & 7.3 & 88 & -25 \\
Standard deviation & 1.4 & 2 & 2 & 1 & 2 & 1 & 0.4 & 1 \\
\hline
\end{tabular}

4.1.2. Dynamic Load Test. Results obtained from the nine unidirectional strain gauges and the two rosettes are shown in Figures 12 and 13, respectively. As previously mentioned, the measurement channels corresponding to strain gauges 6 and 9 were damaged during the journey to the test area, and therefore, no values from these gauges were obtained during the dynamic load test.

The first dynamic load test was conducted between seconds 55 and 57, as can be seen in Figures 12 and 13. The previous variations in strains and stresses corresponded to 


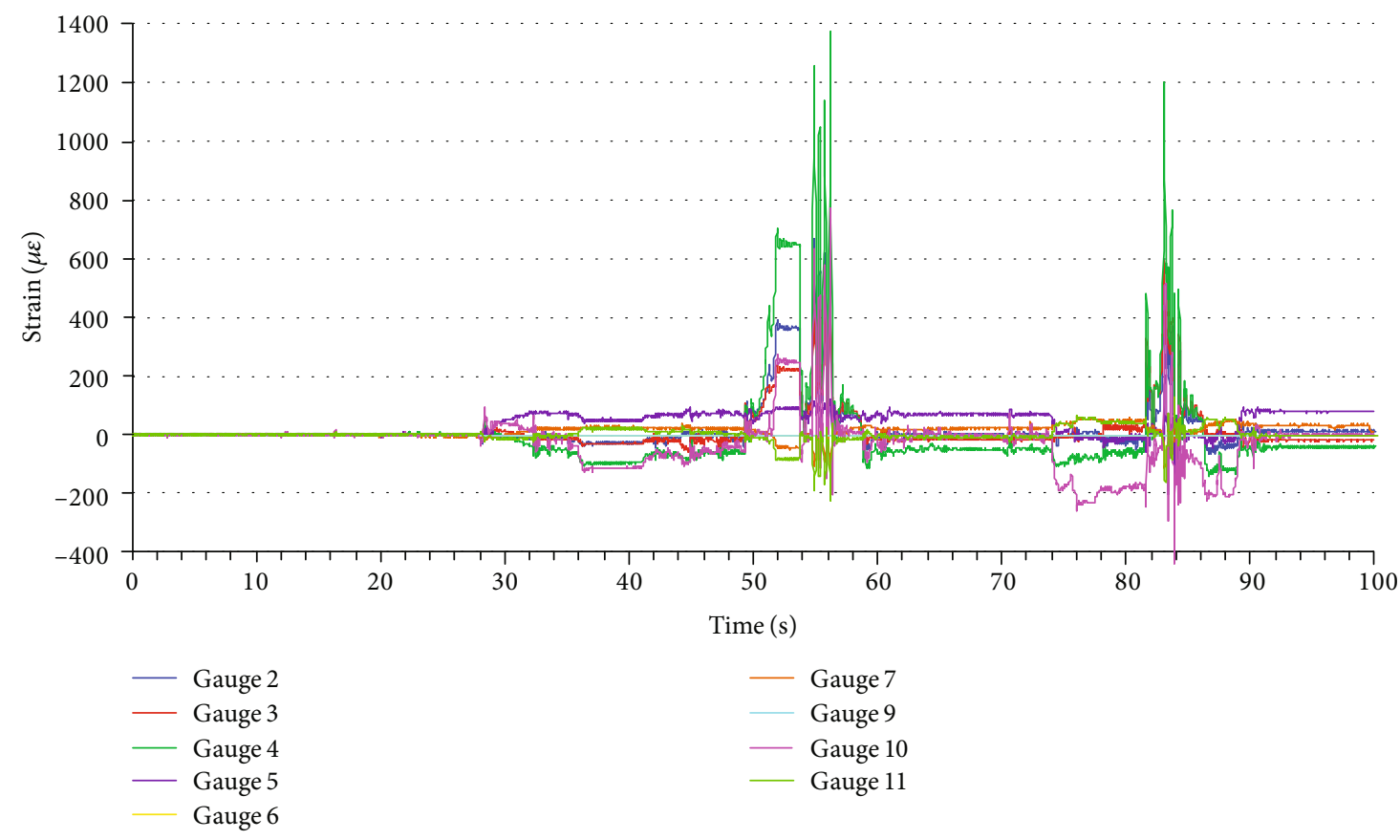

FIGURE 12: Results from unidirectional strain gauges from the dynamic load test.

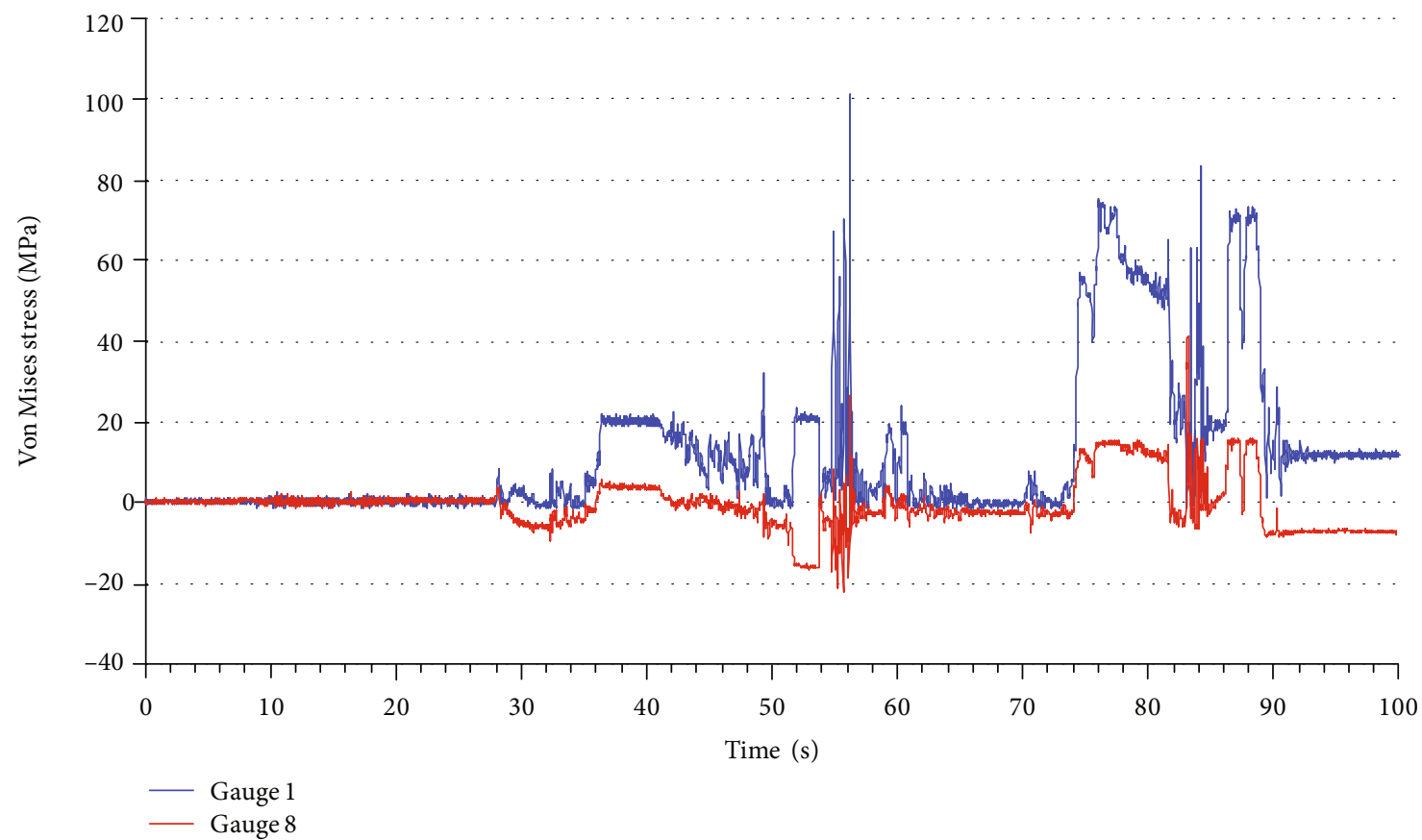

Figure 13: Results from rosettes from the dynamic load test.

different manoeuvres carried out to place the front loader bucket in a position that was perpendicular to the loading bay, so that both longitudinal beams of the front-end loader were balanced. Positioning and load application during the second test started at 73.6 seconds with the load application ending at 84.5 seconds.

Upon analysis of results obtained from dynamic load tests 1 and 2, a clear difference during the test execution can be observed. The variation in the strains and stresses obtained shows differing structural behaviour of the front loader during both tests. This variation in the loader structural behaviour resulted from plastic strains generated in some components of the loader during the execution of the first test.

The maximum strain and stress values obtained during the first experimental dynamic load case are summarised in 
TABLE 4: Maximum strain and stress values from the first dynamic load test.

\begin{tabular}{lcccccccc}
\hline & & \multicolumn{3}{c}{ Gauges } & & & \\
& 1 & 2 & 3 & 4 & 5 & 7 & 10 & 11 \\
\hline Strain $(\mu \varepsilon)$ & - & 734 & 647 & 1,369 & 121 & 41 & - & 770 \\
Von Mises stress $(\mathrm{MPa})$ & 100.9 & - & - & - & - & - & 26.4 & - \\
\hline
\end{tabular}
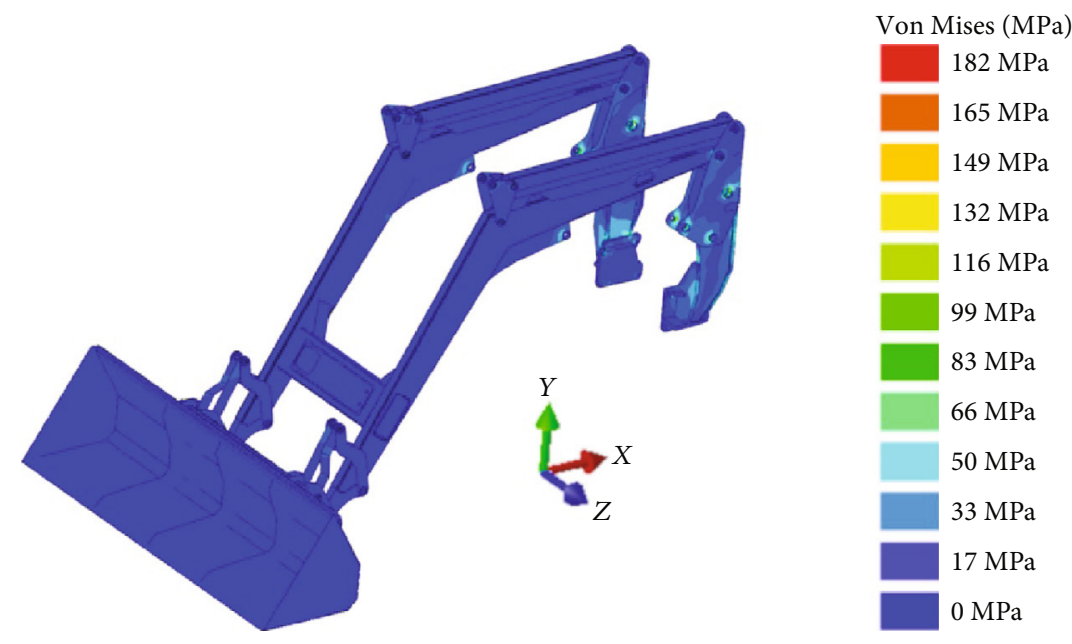

Figure 14: Von Mises stresses (MPa) from the analysis of static load case.

Table 4 . The strains recorded by strain gauges $2,3,4$, and 10 were $734 \mu \varepsilon, 647 \mu \varepsilon, 1369 \mu \varepsilon$, and $770 \mu \varepsilon$, respectively. These results prove that those points where the strain gauges were located recorded significant strains which may lead to plastic strain of the front loader.

The entire analysis of the results obtained at both qualitative level (with the different behaviour of the front loader during the first and second tests) and quantitative level (the strain values recorded mainly from strain gauges $2,3,4$, and 10) proves the need to analyse the structural behaviour of the entire front loader. The results obtained seem to indicate that plastic strains were most likely generated in some structural components of the front-end loader during the execution of the first dynamic load test.

\subsection{Numerical Analysis Phase}

4.2.1. Static Load Case. Figure 14 shows the results for Von Mises stresses obtained from the numerical analysis. The maximum stress values (182 MPa) were located at the upper support bolt of the front loader on the clamping pillar. The higher tensions were located in the support components of the front-end loader in the clamping pillar, as well as in the clamping pillar itself. Nevertheless, the Von Mises stress values obtained, with the exception of the front loader support bolt, were no higher than $110 \mathrm{MPa}$ for the rest of the components.

The maximum value of vertical displacement obtained was $9.99 \mathrm{~mm}$ at the front edge of the bucket, as shown in Figure 15.
The results obtained allow confirming that the design of the front-end loader analysed showed no stiffness or strength issues for the static load case.

Additionally, Table 5 shows strains and Von Mises stress values obtained from the static load case at those points where low-cost sensors were placed for the experimental test.

4.2.2. Dynamic Load Case. Figure 16 shows Von Mises stresses obtained from the numerical analysis. The stress map shows that the stress levels for the front loader in the dynamic load case were far higher than the results from the static load case. More specifically, in the dynamic load case analysed, the maximum stress value was $370 \mathrm{MPa}$ which is higher than the yield strength of Steel S355-JR. This result shows that there are front loader components that get plastically deformed for the dynamic load case. In this instance, those components are the longitudinal beams of the frontend loader, as shown in Figure 16.

Displacement results are shown in Figure 17. The maximum horizontal displacement was $50 \mathrm{~mm}$. These values were placed in the bores of the attachment bolts of the clamping pillars to the tractor. In contrast, displacements were nonexistent at the frontal line nodes of the bucket base. These results are consistent with the boundary conditions imposed in the numerical analysis.

Table 6 shows the strains and Von Mises stresses obtained from the numerical analysis of the front-end loader in the dynamic load case in those points where low-cost sensors were placed for the experimental test model. 

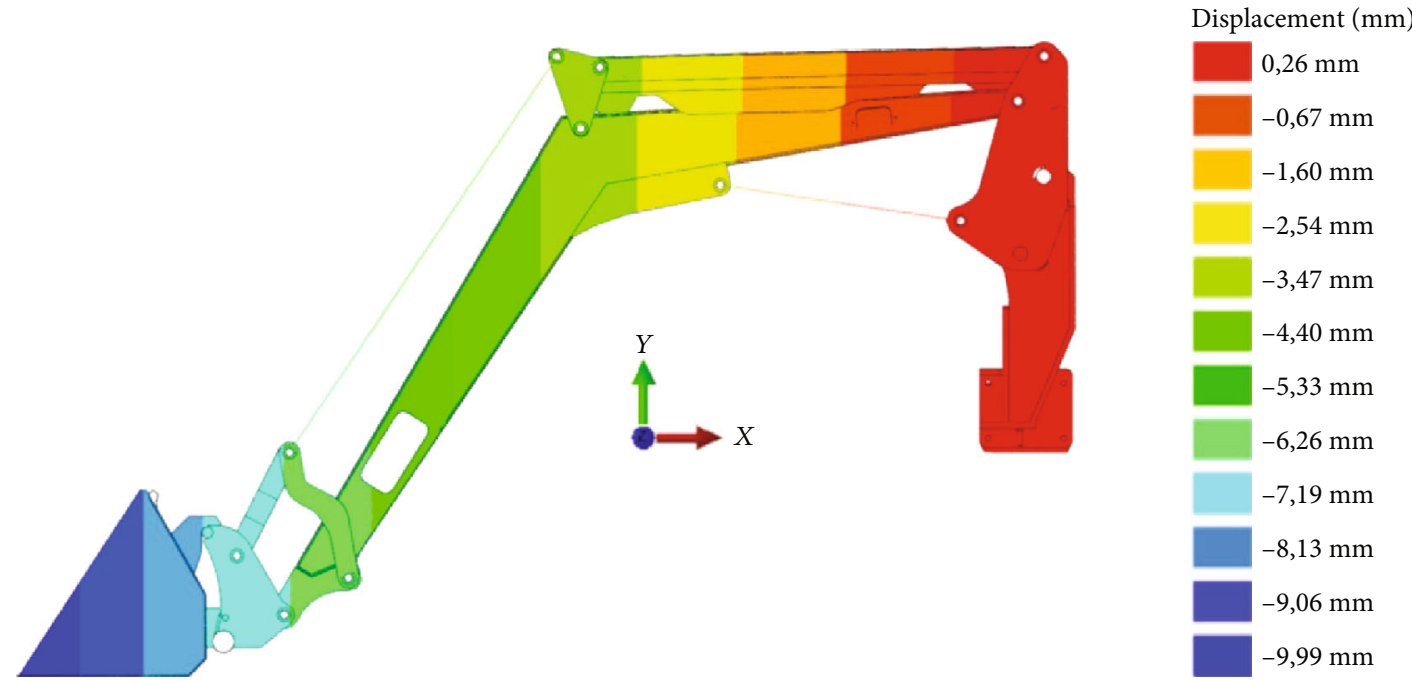

FIGURE 15: Vertical displacements $(\mathrm{mm})$ from the analysis of static load case.

TABLE 5: Strain and stress values for the numerical analysis of static load case.

\begin{tabular}{|c|c|c|c|c|c|c|c|c|c|}
\hline & \multicolumn{9}{|c|}{ Gauges } \\
\hline & 1 & 2 & 3 & 4 & 5 & 7 & 8 & 10 & 11 \\
\hline Strain $(\mu \varepsilon)$ & - & 8 & 9 & 36 & 19 & -7 & - & 79 & -26 \\
\hline Von Mises stress $(\mathrm{MPa})$ & 12.1 & - & - & - & - & - & 7.6 & - & - \\
\hline
\end{tabular}

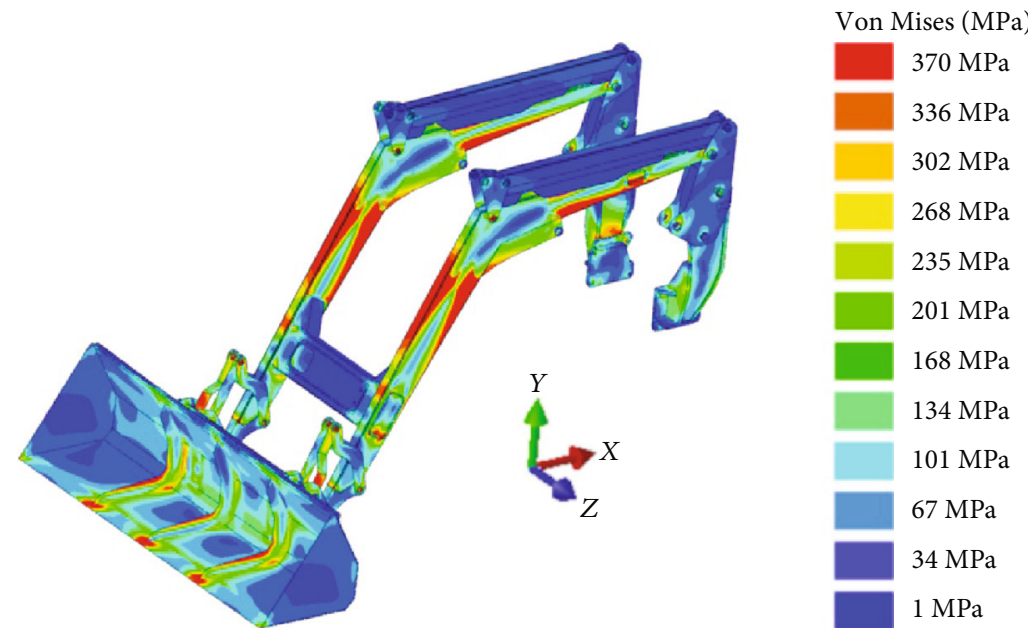

Figure 16: Von Mises stresses (MPa) from dynamic load case.

4.3. Correlation between Experimental and Numerical Results. In a study of this nature, correlation between numerical and experimental results is of paramount importance. On the one hand, correlation between numerical and experimental results allows validating the numerical models used in the study. In this study, this validation allows knowing the structural behaviour of the front-end loader analysed. On the other hand, the validation of the numerical model allows verifying the impressions created from the experimental results recorded by means of the strain gauges of the structural behaviour of the entire front-end loader analysed.
4.3.1. Analysis of the Static Load Case. Table 7 shows the results obtained for a static load case from each of the 9 strain gauges. It also shows the results obtained from the numerical analysis conducted by means of the FEM. Additionally, the error obtained when comparing the numerical results to the experimental results is provided.

Errors obtained from strain gauges $1,5,8$, and 11 were less than $10 \%$, a magnitude regarded as admissible for the correlation of results from the FEM. On the other hand, errors of the values from strain gauges 2 and 3 were $-700 \%$ and $-50 \%$. Values of strains recorded by strain gauges 2 and 3 from the experimental test were $1 \mu \varepsilon$ and $6 \mu \varepsilon$, which were 

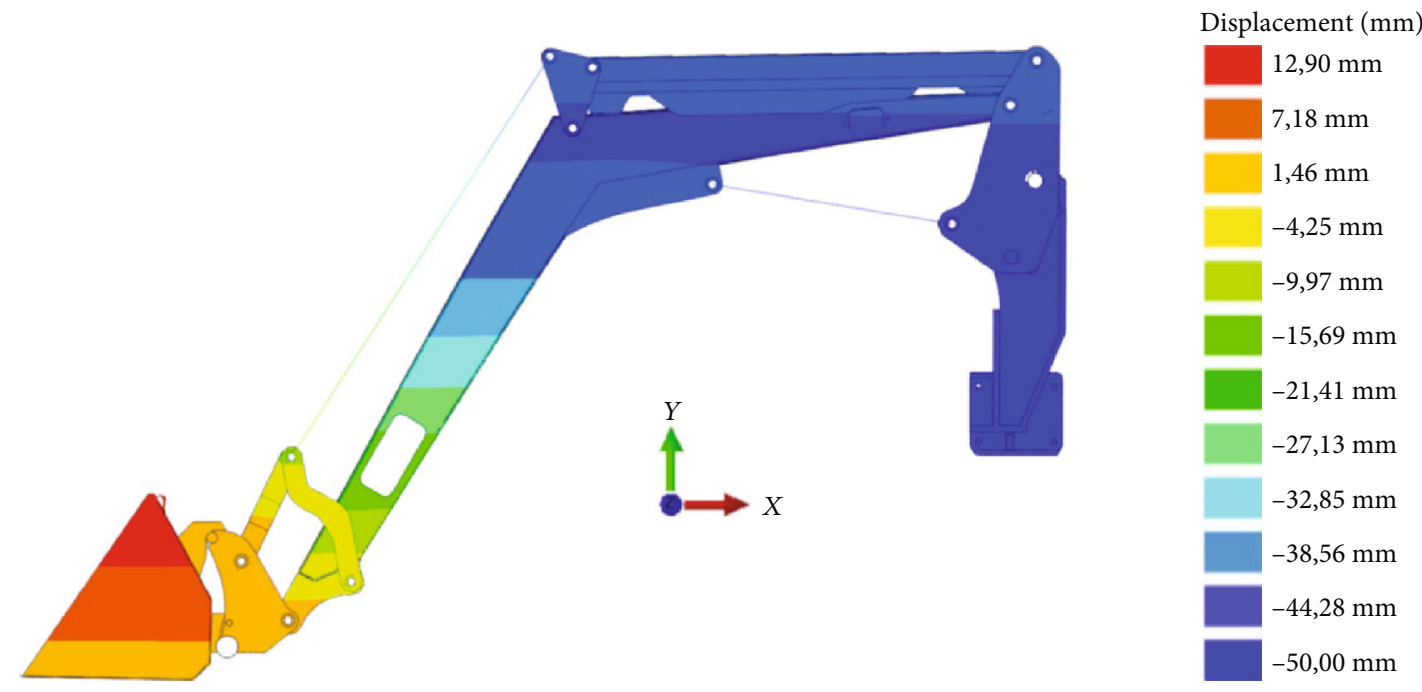

Figure 17: Vertical displacements ( $\mathrm{mm}$ ) from the dynamic load case.

TABLE 6: Strain and stress values for the numerical analysis of dynamic load case.

\begin{tabular}{lccccccccc}
\hline & & \multicolumn{3}{c}{ Gauges } & & \\
& 1 & 2 & 3 & 4 & 5 & 7 & 8 & 11 \\
\hline Strain $(\mu \varepsilon)$ & - & 726 & 711 & 1374 & 129 & -100 & - & 631 & -163 \\
Von Mises stress $(\mathrm{MPa})$ & 90.5 & - & - & - & - & - & 28.3 & - \\
\hline
\end{tabular}

TABLE 7: Correlation of numerical and experimental results from static load case.

\begin{tabular}{|c|c|c|c|c|c|c|c|c|c|c|}
\hline \multirow{2}{*}{ Results } & & \multicolumn{9}{|c|}{ Gauges } \\
\hline & & 1 & 2 & 3 & 4 & 5 & 7 & 8 & 10 & 11 \\
\hline \multirow{2}{*}{ Test } & $\mu \varepsilon$ & - & 1 & 6 & 29 & 18 & -6 & - & 88 & -25 \\
\hline & $\mathrm{MPa}$ & 11.7 & - & - & - & - & - & 7.3 & - & - \\
\hline \multirow{2}{*}{ Numerical analysis } & $\mu \varepsilon$ & - & 8 & 9 & 36 & 19 & -7 & - & 79 & -26 \\
\hline & $\mathrm{MPa}$ & 12.1 & - & - & - & - & - & 7.6 & - & - \\
\hline Error & $\%$ & -3.42 & -700 & -50 & -24.14 & -5.56 & -16.67 & -4.11 & 10.23 & -4.00 \\
\hline
\end{tabular}

very low strain values. Values of strain obtained from the numerical analysis for strain gauges 2 and 3 were $8 \mu \varepsilon$ and $9 \mu \varepsilon$, respectively. The numerical difference of the results from gauges 2 and 3 was $7 \mu \varepsilon$ and $3 \mu \varepsilon$, respectively, that is equivalent to a unidirectional stress of $1.47 \mathrm{MPa}$ and $0.63 \mathrm{MPa}$ for gauges 2 and 3 , which is a minor difference for strain or stress results. Owing to the fact that the strains results were at such low level, the error generated in the correlation of numerical results with respect to experimental results was quite high. Due to the minor differences in numerical value between the experimental and numerical results, $7 \mu \varepsilon$ and $3 \mu \varepsilon$ at the positions for strain gauges 2 and 3, respectively, the numerical error obtained from gauges 2 and 3 is not significant in machinery design and thus allows validating the results obtained by means of numerical techniques in the measuring points of strain gauges 2 and 3 . The relative error between experimental and numerical results obtained from strain gauges 4 and 7 is $24.14 \%$ and $16.67 \%$. Nonetheless, in both cases, the difference between numerical and experimental results is $7 \mu \varepsilon$ for gauge 4 and $1 \mu \varepsilon$ for gauge 7 . This strain values are equivalent to a unidirectional stress of $1.47 \mathrm{MPa}$ and $0.21 \mathrm{MPa}$, respectively. Therefore, and similar to gauges 2 and 3, the relative error obtained from gauges 4 and 7 is not significant in machinery design. The minor differences between experimental and numerical results allow validating the results obtained by means of numerical techniques in the measuring points of strain gauges 4 and 7 . In the case of gauge 10 , the error is $10.23 \%$. This error is considered as admissible.

The results obtained allow concluding that there is good correlation between the numerical and experimental results obtained from the study of a front-end loader 430E2. The good correlation of results allows validating the numerical model of front-end loader, as well as the study of the static 
TABLE 8: Correlation of numerical and experimental results from dynamic load case.

\begin{tabular}{lcccccccccc}
\hline \multirow{2}{*}{ Results } & & \multicolumn{1}{c}{ G } & 1 & 2 & 3 & 4 & 5 & 7 & 8 & 10 \\
\hline \multirow{2}{*}{ Test } & $\mu \varepsilon$ & - & 734 & 647 & 1,369 & 121 & -104 & - & 609 & -178 \\
& $\mathrm{MPa}$ & 93.4 & - & - & - & - & - & 26.4 & - & - \\
\hline \multirow{2}{*}{ Numerical analysis } & $\mu \varepsilon$ & - & 726 & 711 & 1,374 & 129 & -100 & - & 631 & -163 \\
& $\mathrm{MPa}$ & 90.5 & - & - & - & - & - & 28.3 & - \\
\hline Error & $\%$ & 3.10 & 1.09 & -9.89 & -0.37 & -6.61 & 3.85 & -7.2 & -3.61 & 8.43 \\
\hline
\end{tabular}

load case defined during the development of the methodology for the design of front-end loaders.

4.3.2. Analysis of the Dynamic Load Case. Table 8 shows the strain and stress results obtained from the experimental test and the numerical analysis of the dynamic load case. These results correspond to the points in which the strain gauges were placed at the front-end loader. On the other hand, this table provides the error obtained when comparing the numerical results with the results obtained experimentally.

Unlike the static load case where the mass applied $(320 \mathrm{~kg})$ was known, for the dynamic load case, neither the force exerted by the tractor nor its displacement was known. Thus, in order to conduct the correlation of results, it is necessary to find a time period where the results obtained experimentally coincide with the results obtained from the numerical analysis for the dynamic load case.

The experimental results shown in Table 8 were obtained between seconds 56.18 and 56.24 , thus involving a time interval of 0.06 seconds. As shown in Table 8, the error of the results obtained by means of the numerical analysis when compared to the experimental results was under $10 \%$ for the nine measuring points analysed. These errors less than $10 \%$ and a time interval in which they were obtained very small ( 0.06 seconds) allow confirming that the experimental and numerical results have a high correlation. This correlation allows validating the numerical model of front-end loader, as well as the study of the dynamic load case defined during the development of the methodology for the design of front-end loaders.

\section{Conclusions}

This study has shown the steps implemented for the development of a methodology which allows improving the current techniques for design and development of front-end loaders for agricultural tractors. In particular, this methodology analyses the manoeuvre that generates most instances of damage at the front-end loader, i.e., bucket loading.

The methodology developed consists of two phases: one experimental and the other involving numerical analysis. The experimental phase, by making use of low-cost sensors, more specifically 9 strain gauges, has allowed obtaining the strains and stresses generated at specific points of the frontend loader structure. On the other hand, the numerical analysis phase has allowed studying the structural behaviour of the entire front-end loader by means of numerical techniques based on the Finite Element Method.

In the development of the methodology, two load cases, one static and the other dynamic, have been defined. The static case study allowed obtaining the strains and stresses generated in the front-end loader when a known mass was placed onto the bucket. The second load case, a dynamic case, allowed analysing the structural behaviour of the front-end loader during the bucket loading process. In order to ensure the repeatability of the study, the experimental test was defined in such a way that the front part of the bucket coupled to the front-end loader pushed to a concrete loading bay while the tractor moved forward. The numerical analysis for this test was defined in a similar way, limiting the forward movement of the tractor to $5 \mathrm{~cm}$.

The experimental results obtained by means of the nine strain gauges and the results of the numerical analysis from the static load case show high correlation. The difference between the numerical results and the experimental results was lower than $9 \mu \varepsilon$ for the unidirectional strain gauges and $0.4 \mathrm{MPa}$ for the rosettes. This correlation of results allows validating the numerical model for the front-end loader, as well as the static load case defined during the development of the methodology for the design of the front-end loader.

On the other hand, the experimental results and the numerical results obtained from the dynamic load case show high correlation. Concretely, the error of the results obtained by means of the numerical analysis when compared to the experimental results was under $10 \%$ for the nine measuring points analysed. The experimental results were obtained in an interval of 0.06 seconds. This high correlation of results allows validating the numerical model for the front-end loader, as well as the study of the dynamic load case defined during the development of the methodology for the design of front-end loaders.

\section{Data Availability}

The data used to support the findings of this study are available from the corresponding author upon request.

\section{Conflicts of Interest}

The authors declare that there is no conflict of interest regarding the publication of this paper. 


\section{Acknowledgments}

The authors express their gratitude to the cooperative "Virgen de la Oliva, Ejea de los Caballeros," for their assistance with this research. This research was funded by VEHIVIAL Research Group (University of Zaragoza) and by the company Maquinaria Agrícola El León (Spain).

\section{References}

[1] B. J. Cho, S. W. Ahn, C. J. Lee, Y. H. Yoon, S. S. Lee, and H. J. Kim, "Improved design of hydraulic circuit of front-end loader for bump shock reduction of an agricultural tractor," Journal of Drive and Control, vol. 13, no. 2, pp. 10-18, 2016.

[2] Y.-J. Park, S.-B. Shim, and J.-S. Nam, "Experimental study on the structural safety of the tractor front-end loader against impact load," Journal of Biosystems Engineering, vol. 41, no. 3, pp. 153-160, 2016.

[3] Y. J. Kim, S. O. Chung, S. J. Park, and C. H. Choi, “Analysis of power requirement of agricultural tractor by major field operation," Journal of Biosystems Engineering, vol. 36, no. 2, pp. 79$88,2011$.

[4] S. W. Ahn, H. J. Kim, S. S. Lee, and D. S. Choi, "Study on driving shock reduction of a front end loader by accumulator," Korean Society for Agricultural Machinery, vol. 19, no. 1, pp. 91-92, 2014.

[5] P. Simion and S. Nastase, "Contributions to the study of the dynamics of agricultural tractors equipped with front-end loader and rear forklift loader," in 8th International Scientific Conference. Engineering for Rural Development, Jelgava, Latvia, 2009.

[6] G. S. Lim and B. Y. Lee, "Study on the impact analysis of front loader for tractor," Journal of the Korea Academia-Industrial cooperation Society, vol. 16, no. 8, pp. 5051-5059, 2015.

[7] Z. Yu, Z. Shan, J. Yuan, and X. Li, "Performance deterioration of heavy-haul railway bridges under fatigue loading monitored by a multisensor system," Journal of Sensors, vol. 2018, Article ID 5465391, 14 pages, 2018.

[8] A. Gregori, E. di Giampaolo, A. di Carlofelice, and C. Castoro, "Presenting a new wireless strain method for structural monitoring: experimental validation," Journal of Sensors, vol. 2019, Article ID 5370838, 12 pages, 2019.

[9] M. Carrera Alegre, L. Castejon Herrer, H. Malon Litago et al., "Fatigue life analysis of semitrailers. Fatigue testing bench and numerical simulation,” DYNA, vol. 91, no. 4, pp. 406-412, 2016.

[10] H. Malon, L. Castejon, J. Cuartero, and P. Martin-Buro, "Numerical-Experimental analysis of two Floor Platform Designs for auxiliary Construction Truck," Experimental Techniques, vol. 39, no. 6, pp. 53-60, 2015.

[11] H. J. Beermann, "Static analysis of commercial vehicle frames: A hybrid-finite element and analytical-method," International Journal of Vehicle Design, vol. 5, no. 1-2, pp. 26-52, 1984.

[12] C. Karaoğlu and N. S. Kuralay, "Stress analysis of a truck chassis with riveted joints," Finite Elements in Analysis and Design, vol. 38, no. 12, pp. 1115-1130, 2002.

[13] F. Cappello, T. Ingrassia, A. Mancuso, and V. Nigrelli, "Methodical redesign of a semitrailer," in 9th International Conference on Computer Aided Optimum Design in Engineering. Computer Aided Optimum Design in Engineering IX Book
Series: Wit Transactions on the Built Environment, vol. 80, pp. 359-369, 2005.

[14] R. M. Buil and L. C. Herrer, "Diseño Frente a Fatiga De Semirremolques Cisterna. Fatigue design of tanker semi-trailers," Dyna Ingenieria E Industria, vol. 85, no. 3, pp. 480-488, 2010.

[15] Y. Q. Deng, J. G. Wang, Y. Wen, S. Zhao, and L. L. Dai, "The static and dynamic characteristics study of aluminum tank semitrailer," Advanced Materials Research, vol. 189-193, pp. 2233-2237, 2011.

[16] P. Luque, D. A. Mántaras, A. Rodríguez et al., "Low-cost monitoring system of sensors for evaluating dynamic solicitations of semitrailer structure," Journal of Sensors, vol. 2016, Article ID 1740854, 15 pages, 2016.

[17] H. Malon, F. J. Garcia-Ramos, M. Vidal, and A. Bone, "Design and optimization of a chassis for an air-assisted sprayer with two fans using the finite element method," in Project Management and Engineering Research, 2014, pp. 103-115, Springer, Cham, 2016.

[18] H. Malón, A. Aguirre, A. Boné, M. Vidal, and F. GarcíaRamos, "Design and testing of an agricultural implement for underground application of rodenticide bait," Sensors, vol. 15, no. 1, pp. 2006-2020, 2015.

[19] Data Sheet, "Front-end loader 430E2," http://www.el-leon.es/ productos/palas-cargadoras/productos/palas-cargadoras/ copy5_of_serie-europa.

[20] K. Hoffmann, "An Introduction to Measurement Using Strain Gauges," Publisher by Hottinger Baldwin Messtechnik GmbH, Darmstadt (Germany), 1989. 